\title{
EDITORIAL
}

\section{Respiratory education: a dangerous drift away from academia?}

\author{
M. Polkey*, T. Howes ${ }^{\#}$, G. Burns ${ }^{\star}$ and S.G. Spiro ${ }^{+}$
}

$\mathbf{T}$ he education of specialist doctors in respiratory medicine has evolved over a long time. The importance of the clinical apprenticeship was stressed by Hippocrates and evolved through European medicine into the 20th century. Part of this clinical apprenticeship has developed into an early exposure to medical research. A minority of medical students are able to be involved in this process before final examinations, but in past decades junior doctors gained their initial experience during the first few years of their career. Many senior doctors remember these experiences with great fondness. These small pieces of clinical research, and the resultant abstracts at local meetings produced by these junior doctors, sowed the seeds for a life-long interest in medical research.

Over recent years, the taught element of junior doctors' training, at least in the UK, has increased. In many ways, this has benefited the training process. However, the pressures to achieve parity of training across Europe, and to shorten training to meet a perceived need for an expansion in the number of senior doctors to cope with all that respiratory medicine has to cover, has led to a perception that research in training is much less sought after and important to those trainees planning a career in service delivery rather than research, or at least a post with research opportunities.

The considerable increase in formal assessments during junior doctors' training has further limited the time available for clinical research activities. In the UK, the Medical Training Application Service process has extended the formalised assessments used for foundation programme trainees to middle-grade doctors. The use of logbooks of training to record virtually every event has increased. In the UK, trainees in respiratory medicine usually choose to also be trained fully (and consequently assessed) in general internal medicine for accreditation. In many ways, these developments are laudable and may improve overall training (although this has yet to be shown in practice). Whatever benefits may accrue from this, there is no doubt that the available time for clinical, hands-on experience has been reduced.

*Dept of Respiratory Medicine, Royal Brompton Hospital and "Dept of Respiratory Medicine, University College Hospital, London, "Dept of Respiratory Medicine, Colchester General Hospital, Essex and ${ }^{+}$Dept of Respiratory Medicine, Royal Victoria Infirmary, Newcastle upon Tyne, UK.

STATEMENT OF INTEREST: A statement of interest for T. Howes can be found at www.erj. ersjournals.com/misc/statements.shtml

CORRESPONDENCE: S.G. Spiro, Dept of Respiratory Medicine, University College London Hospital NHS Trust, Grafton Way, London WC1E 6AU, UK. Fax: 44 2073809476. E-mail: stephen.spiro @uclh.nhs.uk
These developments in junior doctors' training have coincided with the gradual rolling out of the European working time directive to junior doctors. Juniors in all European countries are managing the conflict between "getting the job done" for their patients and meeting the time requirements of the directive. Many UK hospitals are actively monitoring hours of work, and research activities are included in these assessments of hours worked. A recent article [1] comparing training experiences at the birth of the National Health Service 60 yrs ago claimed that, for the granddaughter of Prof. M. Turner-Warwick to become a consultant today with the same experience as her grandmother, she would require an extra 6 yrs' training in today's environment!

Our concern is about this combination of decreased available time, more pressure from formalised assessment of that time, increasing pressure from general medicine and the ease with which an audit project is termed research. There is a drift toward a growing number of specialists becoming accredited without any personal experience of clinical research and the training research itself provides as a discipline for the future. At least in the UK (see below) the problem may be particularly acute for research in respiratory medicine, which is less well supported relative to other medical specialities.

The British Thoracic Society (BTS) has carried out two surveys recently, one on the future of academic staff in the UK, and the other on what the trainee workforce is doing and wishes to do.

In May 2006, the UK Clinical Research Collaboration showed that respiratory medicine was 13th in a list of 20 specific health categories (one place behind "the ear") ranked by proportion of spend. Looking at the proportion of respiratory consultants who also held academic/research contracts, again our speciality was one of the lowest, with $8 \%$ of consultants. There seems, therefore, an urgent need to increase the capacity of academic respiratory medicine, and a survey of 112 professors from the BTS database obtained an $80 \%$ response. The majority of chair holders did not expect their chair to be replaced upon retirement as they were personal chairs, and $45 \%$ of respondents were due to retire within the next 5 yrs. This led to a calculated loss of $34 \%$ of chairs within 5 yrs and $53 \%$ in 10 yrs. This trend in the care of a group of diseases representing the greatest disease burden of any medical area is alarming, together with respiratory diseases being grossly underrepresented in the current stock of medical researchers, and funding being, until recently, pitiful.

The second BTS survey of 440 specialist trainee registrars (SpRs) obtained a smaller response rate of $36 \%$, and showed 
that only 37 of the 153 respondents had research experience. Of these, most (64\%) were doing this as an SpR, but at the time of the questionnaire, only $32 \%$ had published a peer-reviewed article and $31 \%$ felt they would achieve an $\mathrm{MD}$ or $\mathrm{PhD}$. Funding opportunities were mixed, with only 25\% getting peer-review funding, $28 \%$ being supported by industry and $20 \%$ having university support. Interestingly, nearly $75 \%$ of respondents without research experience said they would contemplate it. The reasons given for not wishing to enter a research programme were salary reduction, not liking it and lack of funding. Only 20\% wanted to become an academic and the rest saw themselves as full-time clinicians. There is, of course, nothing to criticise in the latter ambition, but there has to be concern at the probable shrinkage in the UK academic base and that the majority of SpRs will become consultants with no experience of research methodology. However, it has to be hoped that a projected $20 \%$ base of academic respiratory physicians may be sufficient for the speciality to thrive.

Although training differs to some extent throughout Europe, we must stay vigilant to ensure that regulation does not become the alternative to a proper training for our younger colleagues.

\section{ACKNOWLEDGEMENTS}

The current authors are very grateful to the British Thoracic Society for making the BTS data available to us.

\section{REFERENCES}

1 Timmins N. Patients safer under old regime, doctors say. Financial Times; July, 4: 2008. 